\title{
The effects of Sorbinil on peripheral nerve conduction velocity, polyol concentrations and morphology in the streptozotocin-diabetic rat
}

\author{
N.E.Cameron, M. B. Leonard, I.S. Ross and P.H. Whiting \\ Departments of Physiology and Chemical Pathology, University of Aberdeen, UK
}

\begin{abstract}
Summary. This study examined the effects of an aldose reductase inhibitor, Sorbinil, on neuropathy over a 6-month period in streptozotocin-diabetic rats. Sorbinil treatment prevented the 10-fold increase in nerve sorbitol found with diabetes. It produced a $60 \%$ improvement in tibial nerve motor conduction velocity after 6 months. Morphometric profiles of nerves were also normalised. Axon area was reduced by $14 \%$ in untreated diabetic rats compared to age-matched controls, whereas Sorbinil-treated animals showed normal age-related axon growth. Myelin area was increased by $28 \%$ in untreated diabetic animals, but was the same as age-matched controls
\end{abstract}

with Sorbinil treatment. Nerve myo-inositol levels were reduced by $45 \%$ after three months of untreated diabetes, but were normal after six months. Sorbinil treatmend tended to restore $m y o$-inositol levels toward normal over the shorter time period. It was concluded that axon growth retardation is the most likely cause of the conduction deficit seen in longterm experimental diabetes.

Key words: Diabetes, aldose reductase, neuropathy, nerve conduction, axon, myelin, Sorbinil, polyol pathway.
Biochemical, functional and morphological abnormalities are commonly found in the peripheral nerves of human diabetic patients, and similar changes are seen in animal models. The streptozotocin-diabetic rat exhibits increased polyol pathway activity [1], altered myo-inositol metabolism, and reductions in both nerve conduction velocity [2] and axonal transport [3]. Morphological changes in the nerve fibres themselves include a reduced fibre diameter, primarily caused by a decrease in axon size [4].

There is evidence to link functional deficits with enhanced polyol pathway activity. Gabbay [1] suggested that sugar alcohol accumulation in nerves caused osmotic damage leading to reduced conduction velocity. Greene et al. [5] considered that the conduction deficit depended on the reduction of myo-inositol content which results when sorbitol accumulates in peripheral nerves.

Inhibitors of aldose reductase, the first enzyme in the polyol pathway, may have a role in the amelioration of peripheral nerve abnormalities [6]. In diabetic rats, aldose reductase inhibitor treatment has been found to improve conduction velocity [7], reduce polyol and restore myo-inositol levels [8], and to enhance axonal transport [9]. However, there is disagreement in the literature; treatments that increase diabetic nerve myo- inositol content do not necessarily improve conduction velocity [10]. One aim of the present investigation was to provide further information on this point. In addition, the effects of aldose reductase inhibitors on nerve morphology have not been investigated. The major aim of this study was to correlate biochemical, functional and morphological data from the same animals in order to provide further information on the changes occuring in diabetes, the role of the polyol pathway, and the preventative efficacy of Sorbinil.

\section{Materials and methods}

\section{Animals and experimental groups}

Seven groups of male Sprague-Dawley rats from the University Animal Department, Aberdeen, UK were used. Three acted as normal controls, with one being an onset group (aged 19 weeks, $n=9$ ) to provide a starting point for comparison with other groups. The other animals survived for 3 or 6 months longer to act as age-matched controls (3 month $\mathrm{AC}, n=9$, and 6 month $\mathrm{AC}, n=9$ ).

Four groups were made diabetic at 19 weeks of age by intraperitoneal injection of streptozotocin $(45 \mathrm{mg} / \mathrm{kg})$ in $20 \mathrm{mmol} / \mathrm{l}$ sodium citrate buffer ( $\mathrm{ph} 4.5$ ). Diabetes was verified $24 \mathrm{~h}$ later by the presence of hyperglycaemia and glycosuria (Visidex II and Diastix, Ames, Slough, UK). Blood glucose was subsequently monitored at regular intervals. Final values were measured by gas liquid chromatography 
on samples taken during experiments. Preliminary investigations on rats of the same age, sex and strain, given the same dose of streptozotocin, revealed a metabolic state of hyperosmolar but nonacidotic diabetes. Two of these groups were killed 3 or 6 months later and acted as diabetic controls ( 3 month DC, $n=9$, and 6 month DC, $n=11$ ). Sorbinil (CP 45634; Pfizer, Sandwich, UK, $25 \mathrm{mg} / \mathrm{kg}$ ) was administered daily to the other 2 groups by gavage. It was dissolved in $0.1 \mathrm{~N} \mathrm{NaOH}$ then neutralised to $\mathrm{pH} 7.0$ with $\mathrm{HCl}$. Sorbinil-treated diabetic animals had survival times of 3 or 6 months, and were referred to as 3 -month $(n=10)$ and 6-month $(\mathrm{n}=10)$ DS groups respectively.

All rats were maintained on standard laboratory diet containing $0.03 \%$ myo-inositol, with water ad libitum. In final experiments, conduction velocity measurements and tissue samples were taken before killing by exsanguination.

\section{Conduction velocity}

Animals were anaesthetised with intraperitoneally injected urethane $(1-1.5 \mathrm{~g} / \mathrm{kg})$. Rectal temperature was kept at $37.5-38.5^{\circ} \mathrm{C}$ using a heated pad. The right sciatic nerve was exposed at the notch and a thermistor probe was passed along it to a point near the knee midway between the two stimulating positions. This temperature monitor was used to control radiant heat supplied to the leg to match nerve and core temperatures within $1{ }^{\circ} \mathrm{C}$.

Bipolar stimulating electrodes were placed at the sciatic notch and ankle. A bipolar recording electrode was inserted into the muscle of the first interosseus space of the foot. Supramaximal $0.1 \mathrm{~ms}$ stimuli were delivered at $1 \mathrm{~Hz}$. Muscle potentials were amplified, filtered between $10 \mathrm{~Hz}$ and $10 \mathrm{KHz}$, and displayed on an oscilloscope. Ninetysix potentials, evoked by either ankle or notch stimulation, were summed using a signal averager which also provided hard copy of the averaged electromyograms. Interelectrode distance was estimated with vernier calipers.

\section{Nerve and plasma polyol estimation}

Sciatic nerves were cleared of surrounding tissue, removed, frozen in liquid nitrogen, and stored at $-80^{\circ} \mathrm{C}$. Thawed nerves were weighed and boiled for $20 \mathrm{~min}$ in distilled water containing $\alpha$-methyl mannoside as the internal standard. Deproteinised Somogyi supernatents were lyophilised. Plasma samples were deproteinised and treated in a similar fashion.

Myo-inositol and free sugars in freeze-dried nerve and plasma extracts were converted into their trimethylsilyl ethers [11]. Samples were run on a gas liquid chromatograph (Pye-Unicam 304, Cambridge, UK) equipped with hydrogen-flame-ionisation detectors.

\section{Morphology}

A portion of the left tibial nerve from a standard position between knee and ankle was removed, fixed in $0.2 \mathrm{~mol} / 1$ cacodylate buffer with $2.5 \%$ gluteraldehyde, postfixed in $1 \%$ osmium tetroxide, and embedded in araldite resin. Semithin $(0.5 \mu \mathrm{m})$ ultramicrotome sections were stained with thionine and counterstained with acridine orange.

Light microscopy photomontages of the nerves were constructed, and divided into a grid of approximately 100 squares. 8-10 squares were randomly selected, with the constraint that no selected square could border another one, so that sampling was spread across the whole fascicle. All fibres within an area were measured, excluding Schmidt-Lanterman incisures and paranodal regions. The number of fibres sampled per nerve was approximately 200 , and the effective magnification was $1200 \mathrm{X}$. Measurements were made with the aid of a digitising tablet and microcomputer. Fibre diameter was estimated from fibre area as the diameter of an equivalent area circle [12]. For fibres with an area greater than $20 \mu \mathrm{m}^{2}$, measurements were also made of axon area, myelin area, and axon circularity [13]. The fractional area of the fascicle not occupied by myelinated nerve fibres or blood vessels may be defined as the "endoneurial fraction" and was estimated using a point counting technique [4].
Table 1. Sciatic nerve polyol levels

\begin{tabular}{llll}
\hline Experimental group & $\begin{array}{l}\text { Sorbitol } \\
\text { (mmol/kg } \\
\text { wet wt.) }\end{array}$ & $\begin{array}{l}\text { Fructose } \\
\text { (mmol/kg } \\
\text { wet wt.) }\end{array}$ & $\begin{array}{l}\text { Myo-inositol } \\
\text { (mmol } / \mathrm{kg} \\
\text { wet wt.) }\end{array}$ \\
\hline $\begin{array}{l}\text { Normal controls } \\
\text { Onset }(n=9)\end{array}$ & $0.66 \pm 0.07$ & $1.43 \pm 0.14$ & $4.80 \pm 0.40$ \\
3 months $(n=9)$ & $0.38 \pm 0.04$ & $1.11 \pm 0.11$ & $4.18 \pm 0.42$ \\
6 months $(n=9)$ & $0.39 \pm 0.06$ & $1.71 \pm 0.24$ & $4.55 \pm 0.47$ \\
Diabetic controls & & & \\
3 months $(n=9)$ & $2.81 \pm 0.34^{\mathrm{a}}$ & $5.74 \pm 0.59^{\mathrm{a}}$ & $2.31 \pm 0.32^{\mathrm{a}}$ \\
6 months $(n=11)$ & $4.21 \pm 0.35^{\mathrm{a}} \mathrm{d}$ & $9.18 \pm 0.92^{\mathrm{a}, \mathrm{d}}$ & $3.99 \pm 0.47^{\mathrm{d}}$ \\
Sorbinil-treated & & & \\
3 months $(n=10)$ & $0.39 \pm 0.06^{\mathrm{c}}$ & $2.60 \pm 0.38^{\mathrm{b}, \mathrm{c}}$ & $3.37 \pm 0.32$ \\
6 months $(n=10)$ & $0.35 \pm 0.07^{\mathrm{c}}$ & $3.21 \pm 0.38^{\mathrm{c}}$ & $4.20 \pm 0.56$ \\
\hline
\end{tabular}

Results are expressed as mean \pm SEM. ${ }^{a, b}$ compared with normal agematched control $(p<0.01, p<0.05)$, ${ }^{\mathrm{C}}$ effect of Sorbinil, compared with diabetic control $(p<0.01)$. ${ }^{\mathrm{d}}$ different from same treatment group at 3 months $(p<0.01)$

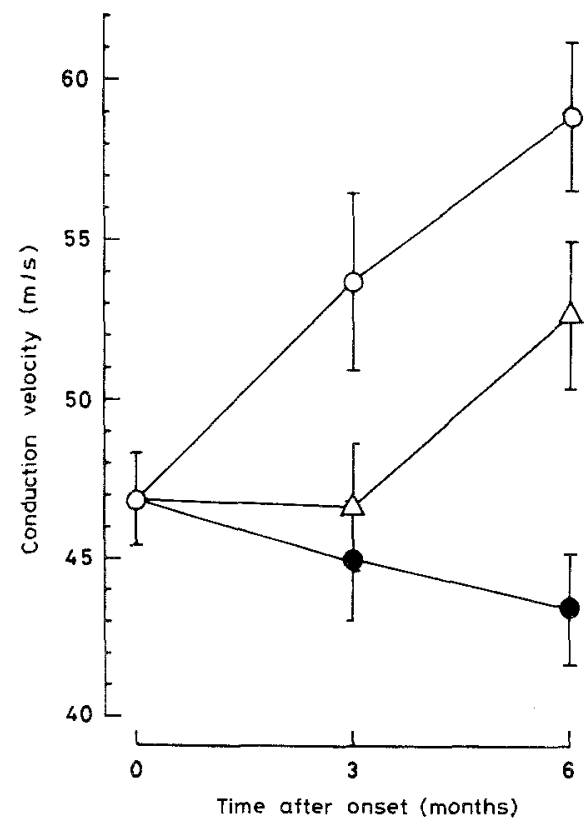

Fig. 1. Tibial motor nerve conduction velocities. Group mean values are shown, and limit bars denote SEM. $O=$ non-diabetic animals at onset $(n=9)$, and after $3(n=9)$ and $6(n=9)$ months (AC). $=$ diabetic control (DC) animals surviving for $3(n=9)$ or $6(n=11)$ months. $\Delta=$ diabetic animals given Sorbinil treatment (DS) for $3(n=10)$ or 6 $(n=10)$ months. Statistical analysis; onset versus AC, - Three months $p<0.01 ; 6$ months $p<0.01$. AC versus DC, 3 months $p<0.05$; 6 months $p<0.01$. AC versus DS, 3 months $p<0.05$. DS versus DC, 6 months $p<0.05$. Onset versus DS, 6 months $p<0.05$. All other comparisons NS

\section{Statistical analysis}

Data values are presented as mean \pm SEM. Significance levels were estimated using analysis of variance followed by the Duncan multiple range test.

\section{Results}

Plasma glucose concentrations were significantly ( $p<$ $0.01)$ elevated from the normal control value of $6.3 \pm$ $0.1 \mathrm{mmol} / \mathrm{l}$ in all diabetic groups. Measured on the day 
Table 2. Morphometric measurements on the tibial nerve

\begin{tabular}{|c|c|c|c|c|}
\hline Experimental group & $\begin{array}{l}\text { Mean fibre } \\
\text { diameter }(\mu \mathrm{m})\end{array}$ & $\begin{array}{l}\text { Small pop. } \\
\text { diameter }(\mu \mathrm{m})\end{array}$ & $\begin{array}{l}\text { Large pop. } \\
\text { diameter }(\mu \mathrm{m})\end{array}$ & $\begin{array}{l}\text { Endoneurial } \\
\text { fraction }\end{array}$ \\
\hline $\begin{array}{l}\text { Normal controls } \\
\text { Onset }(n=9) \\
3 \text { months }(n=9) \\
6 \text { months }(n=9)\end{array}$ & $\begin{array}{l}5.95 \pm 0.14 \\
6.37 \pm 0.19^{\mathrm{a}} \\
6.59 \pm 0.09^{\mathrm{a}}\end{array}$ & $\begin{array}{l}3.31 \pm 0.11 \\
3.30 \pm 0.08 \\
3.28 \pm 0.08\end{array}$ & $\begin{array}{l}6.86 \pm 0.09 \\
7.51 \pm 0.11^{\mathrm{a}} \\
7.64 \pm 0.10^{\mathrm{a}}\end{array}$ & $\begin{array}{l}0.529 \pm 0.020 \\
0.523 \pm 0.025 \\
0.509 \pm 0.024\end{array}$ \\
\hline $\begin{array}{l}\text { Diabetic controls } \\
3 \text { months }(n=9) \\
6 \text { months }(n=11)\end{array}$ & $\begin{array}{l}6.43 \pm 0.10^{\mathrm{a}} \\
6.74 \pm 0.08^{\mathrm{a}}\end{array}$ & $\begin{array}{l}3.17 \pm 0.08 \\
3.19 \pm 0.09\end{array}$ & $\begin{array}{l}7.46 \pm 0.15^{\mathrm{a}} \\
7.88 \pm 0.10^{\mathrm{ab}}\end{array}$ & $\begin{array}{l}0.470 \pm 0.015 \\
0.496 \pm 0.020\end{array}$ \\
\hline $\begin{array}{l}\text { Sorbinil-treated } \\
3 \text { months }(n=10) \\
6 \text { months }(n=10)\end{array}$ & $\begin{array}{l}6.55 \pm 0.12^{\mathrm{a}} \\
6.38 \pm 0.11^{\mathrm{a}}\end{array}$ & $\begin{array}{l}3.33 \pm 0.12 \\
3.08 \pm 0.08\end{array}$ & $\begin{array}{l}7.42 \pm 0.10^{\mathrm{a}} \\
7.36 \pm 0.12^{\mathrm{ac}}\end{array}$ & $\begin{array}{l}0.497 \pm 0.013 \\
0.514 \pm 0.017\end{array}$ \\
\hline
\end{tabular}

Results are expressed as mean \pm SEM. ${ }^{a}$ Different from onset $(p<0.01) ;{ }^{b}$ different from same treatment group at 3 months ( $\left.p<0.05\right) ;{ }^{\mathrm{c}}$ effect of Sorbinil, compared with diabetic control $(p<0.01)$

of the final experiments, they were $36.6 \pm 3.6,55.1 \pm 3.6$, $41.2 \pm 2.4$, and $52.1 \pm 6.2 \mathrm{mmol} / 1$ for 3 - and 6-month DC and DS groups respectively. There was no significant difference between DC and DS groups for the two different time periods, indicating that Sorbinil treatment had no effect on this variable. However, there was a trend for glucose concentration to be higher in the 6 month groups, which was significant $(p<0.01)$ for DC animals.

Plasma fructose, sorbitol and myo-inositol concentrations in normal animals were $0.47 \pm 0.05,0.14 \pm 0.03$ and $0.08 \pm 0.06 \mathrm{mmol} / 1$ respectively, and were unaffected by diabetes or Sorbinil treatment. Cataract formation was obvious on visual inspection of the eyes in most of the 3-month and all of the 6-month DC animals. No cataracts were seen in Sorbinil-treated groups.

Starting weights for animals in all groups were not significantly different and were in the range $554 \pm 18$ to $588 \pm 24 \mathrm{~g}$. AC groups gained weight during the experimental period to reach $716 \pm 25 \mathrm{~g}$ by 3 months and $721 \pm 23 \mathrm{~g}$ by 6 months. Diabetic animals had a $30 \%$ weight loss over the first 3 months, reaching $403 \pm 11 \mathrm{~g}$ in the DC and $388 \pm 17 \mathrm{~g}$ in the DS group. There was little further change to 6 months, with the mean weights $411 \pm 12 \mathrm{~g}$ and $380 \pm 18 \mathrm{~g}$ for DC and DS groups respectively.

\section{Sciatic nerve polyol levels}

Nerve polyol concentrations are summarised in Table 1. Sorbitol and fructose levels were elevated in the DC groups. This increase, for both polyols, was greater at 6 than 3 months $(p<0.01)$. Sorbinil treatment resulted in normal sorbitol and reduced fructose concentrations. Myo-inositol levels were reduced by $45 \%$ in DC compared to $\mathrm{AC}$ groups at 3 months, but the reduction was only $11 \%$ at 6 months. Sorbinil-treated animals had normal myo-inositol levels at 6 months, but they were $25 \%$ reduced at 3 months, although this was not statistically significant.

\section{Motor nerve conduction velocity}

Data for all groups are plotted in Figure 1. Non diabetic animals showed an age-related conduction velocity increase. From the onset level it had risen by $15 \%$ at 3 months and by a further $10 \%$ at 6 months. The difference between 3 and 6 months was not significant, but conduction velocity for both groups was greater than for the onset group.

The DC groups showed little change with age. Conduction velocity remained at onset levels and was significantly slowed compared with $\mathrm{AC}$ groups at 3 and 6 months. Sorbinil treatment increased velocity towards normal levels. This was not statistically significant at 3 months. However, at 6 months, DS conduction velocity was significantly faster than for the DC group and not significantly different from $\mathrm{AC}$ values.

\section{Morphometry}

Table 2 summarises the morphometric data from all groups. There was no evidence of endoneural expansion in diabetic animals. The AC and DS groups showed similar age-related mean fibre diameter increases between onset and 3 months, but not between 3 and 6 months. DC groups also showed an increase between onset and 3 months, and there was a further increase between 3 and 6 months.

Fibre diameter histograms were constructed for all groups (Fig. 2). They appeared bimodal. A probability analysis of cumulative diameter distributions for individual animals [14] resolved them into small and large diameter fibre populations. No significant differences were found between the proportions (24\%) of fibres in the small population, or their mean diameter in any experimental groups. All the changes with age or diabetes were restricted to the larger fibres. Thus, fibre growth between onset and 3 months was similar in AC and DS groups, and there was little further growth between 3 and 6 months. The DC groups, however, exhibited an additional diameter increase between 3 and 

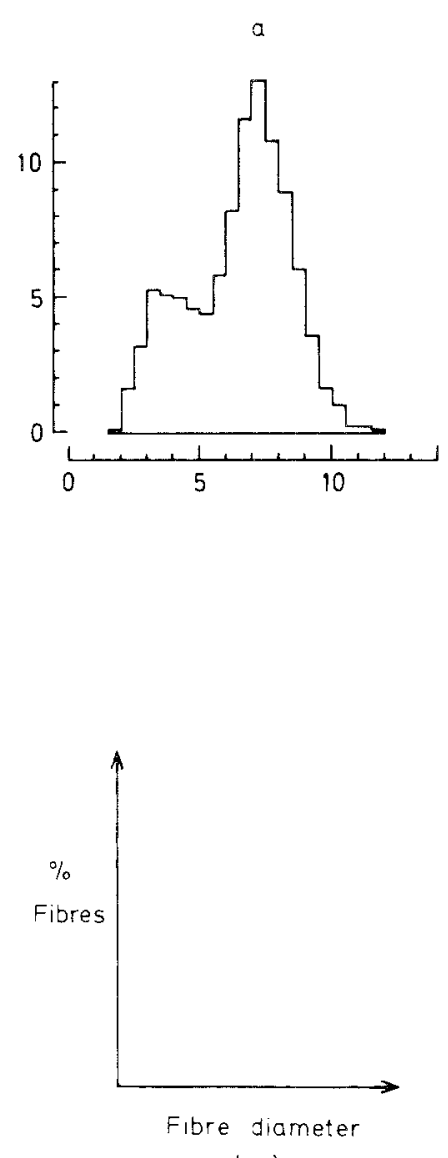

$(\mu)$

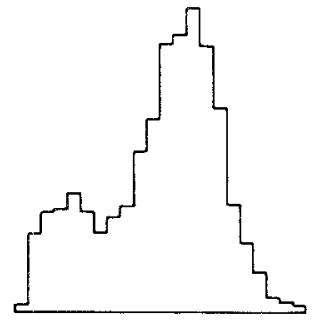

d

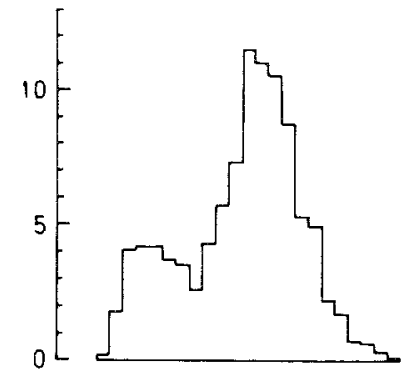

$f$

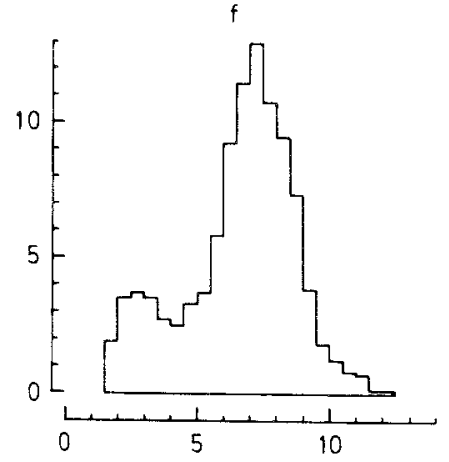

$c$

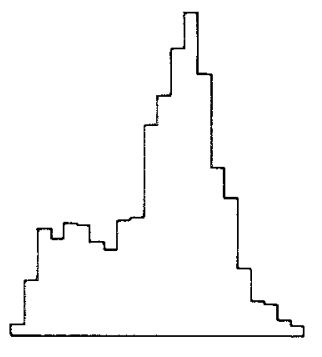

e

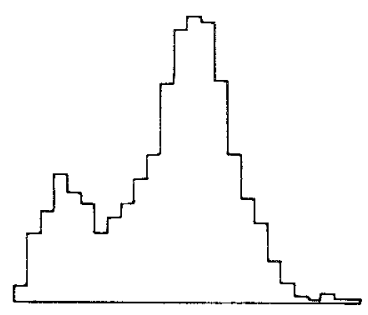

9

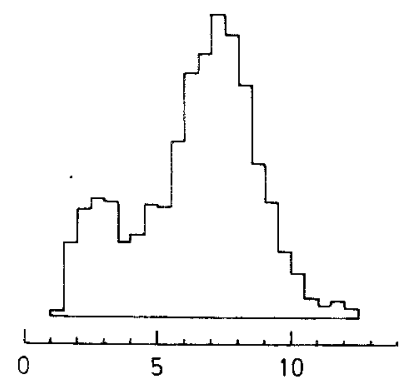

Fig. 2a-g. Tibial nerve myelinated fibre diameter distributions. Group mean values are shown in $0.5 \mu \mathrm{m}$ bins. Non-diabetic control rats at onset $(\mathbf{a}, n=9)$ and age-matched at 3 (b, $n=9)$ and 6 (c, $n=9)$ months. Diabetic control rats at 3 (d, $n=9)$ and $6(\mathbf{e}, n=11)$ months. Sorbinil-treated diabetic rats after $3(\mathrm{f}, n=10)$ and $6(\mathrm{~g}, n=10)$ months

Table 3. Morphometric profile of fibres with $>20 \mu \mathrm{m}^{2}$ area

\begin{tabular}{|c|c|c|c|c|c|}
\hline Experimental group & $\begin{array}{l}\text { Fibre area } \\
\left(\mu \mathrm{m}^{2}\right)\end{array}$ & $\begin{array}{l}\text { Axon area } \\
\left(\mu \mathrm{m}^{2}\right)\end{array}$ & $\begin{array}{l}\text { Myelin area } \\
\left(\mu \mathrm{m}^{2}\right)\end{array}$ & $\begin{array}{l}\text { Axon/myelin } \\
\text { ratio }\end{array}$ & $\begin{array}{l}\text { Axon } \\
\text { circularity }\end{array}$ \\
\hline \multicolumn{6}{|c|}{ Normal controls ( $n=9$ all groups) } \\
\hline 3 months & $45.4 \pm 1.4^{\mathrm{a}}$ & $20.5 \pm 0.9^{b}$ & $24.9 \pm 0.8^{\mathrm{a}}$ & $0.85 \pm 0.04$ & $0.876 \pm 0.007$ \\
\hline 6 months & $46.8 \pm 0.9^{\mathrm{a}}$ & $22.0 \pm 0.7^{2}$ & $24.7 \pm 0.6^{\mathrm{a}}$ & $0.93 \pm 0.03$ & $0.881 \pm 0.005$ \\
\hline \multicolumn{6}{|c|}{ Diabetic controls ( $n=9,3$ months: $n=11,6$ months) } \\
\hline \multicolumn{6}{|c|}{ Sorbinil-treated ( $n=10$ both groups) } \\
\hline 3 months & $45.7 \pm 1.2^{\mathrm{a}}$ & $20.4 \pm 0.6^{b, f}$ & $25.3 \pm 0.6^{\mathrm{a}, \mathrm{g}}$ & $0.83 \pm 0.01^{\mathrm{f}}$ & $0.870 \pm 0.008^{\mathrm{b}}$ \\
\hline 6 months & $45.7 \pm 1.3^{a_{1} g}$ & $21.1 \pm 0.6^{\mathrm{a}, \mathrm{g}}$ & $24.6 \pm 0.8^{\mathrm{a}, \mathrm{f}}$ & $0.89 \pm 0.02^{f}$ & $0.863 \pm 0.004^{\mathrm{a}}$ \\
\hline
\end{tabular}

Results are expressed as mean \pm SEM. ${ }^{\text {a, b }}$ Different from onset $(p<0.01, p<0.05)$; ${ }^{c, d}$ different from normal age-matched control $(p<0.01, p<$ $0.05)$; ${ }^{\mathrm{e}}$ different from same treatment group at 3 months $(p<0.05) ; \mathrm{f}, \mathrm{g}$ effect of Sorbinil, compared with diabetic control $(p<0.01, p<0.05)$

6 months. This trend was exaggerated for the largest fibres in the nerve. Thus, for the top 5 percentile of the large population at 6 months, mean diameters were $9.78 \pm 0.15$ and $10.27 \pm 0.13 \mu \mathrm{m}$ for $\mathrm{AC}$ and $\mathrm{DC}$ groups respectively $(p<0.05)$. The value for the DS group was $9.70 \pm 0.17 \mu \mathrm{m}$, which was not significantly different from normal.
Because of the difficulties associated with the accurate measurement of fine detail by light microscopy with semithin sections for the smaller myelinated fibres [12], only those with a diameter of $>5.05 \mu\left(>20 \mu^{2}\right.$ area) were further examined. This value was chosen because it provided a good separation between small and large diameter fibre populations, excluding $95 \%$ of the 
former and including $95 \%$ of the latter. Fibre area, axon area and circularity, and myelin area were measured for these fibres, which constituted $75 \%$ of the sample. Results are given in Table 3. Mean fibre area followed the same trends as described previously for the large population diameter. Axon area changes showed a different pattern. There was evidence of similar growth from onset values at 3 months in AC and DS groups but little change between 3 and 6 months. However, in the DC groups, axon area remained at onset levels throughout the 6-month period. Consequently, they were significantly smaller than AC and DS values at both 3 and 6 months.

Axon circularity was also significantly reduced in DC animals compared with AC groups at both 3 and 6 months. DS group values were intermediate between $\mathrm{AC}$ and DC levels. At 3 months they were not significantly different from either group. At 6 months they were lower than $\mathrm{AC}$ values, and tended to be higher than for DC animals. This trend towards greater circularity with Sorbinil treatment in diabetes was confirmed by subjecting 3 and 6 month DC and DS group data to a 2 factor hierarchical analysis of variance $(p<0.05)$. The reduced axon circularity in untreated diabetic animals was not related to their reduced area because onset animals, which had similar axon areas, also had greater circularity than 3 or 6 month DC groups.

Similar age-related increases in myelin area were observed in AC and DS groups between onset and 3 months, but there was little further growth between 3 and 6 months. DC animals had even greater increases in myelin area compared with $\mathrm{AC}$ and DS groups at both 3 and 6 months. The combination of reduced axon area and increased myelin area in DC animals resulted in a significant decrease in axon/myelin area ratio, compared with AC and DS groups at both 3 and 6 months.

\section{Discussion}

This study demonstrates that the aldose reductase inhibitor, Sorbinil, prevented sorbitol and fructose accumulation in peripheral nerves of diabetic animals over a 6-month period. Presumably as a consequence of this action, morphometric profiles of nerve fibres were largely normalised and conduction velocity was improved.

The conduction velocity increases with age observed in non-diabetic animals are in close agreement with previous measurements [15]. Untreated diabetic animals showed little evidence of functional maturation, in agreement with several other reports $[2,16,10]$ for the tibial nerve in rats of roughly comparable age. A similar pattern of conduction velocity changes has been reported in spontaneously diabetic rats [17], suggesting that the present findings resulted from the effects of diabetes rather than their being caused by any direct neurotoxic effect of streptozotocin. Some reports have noted a large drop in tibial conduction velocity below levels found at the onset of diabetes [18]. Most, but not all [9], of these results can be explained on methodological grounds, particularly by lack of control over nerve temperature [10]. Thermal insulation loss caused by muscle wasting and fat depot mobilisation results in lower nerve temperatures, particularly when thermoregulatory responses are depressed by anaesthesia. Thus, even if nerves in diabetic animals were normal, apparent conduction velocity would drop below control values without rigorous temperature control. The present results therefore suggest that a failure of normal maturation is the main cause of reduced conduction velocity in the tibial nerves of diabetic rats.

This conclusion is supported by the morphometric data. Thus, the pattern of axon growth in the larger myelinated fibres closely paralleled the trend shown in the conduction velocity data. Axon area remained at onset levels, as did conduction velocity in untreated diabetic rats, whereas normal animals showed age-related increases in both these parameters. The retardation in axon growth is in agreement with other light and electron microscopy studies $[4,13,19]$ using relatively mature rats, although Zemp et al. [20] found that axons grew normally when diabetes was induced in very immature animals. The reason for such age-related differences is not known and requires further investigation, but paradoxically it appears that diabetes during the rapid growth phase has less effect on axons than when they are more fully developed.

In the present study, Sorbinil administration had a beneficial effect by reducing the conduction velocity difference between diabetic and age-matched normal rats by $19 \%$ and $60 \%$ after 3 and 6 months respectively. Yue et al. [7] demonstrated a similar effect starting with younger animals over a 9-month period. However, they did not control nerve temperature. While their data suggest a normalising effect of Sorbinil, it is not possible to quantify direct effects on the nerves as opposed to other factors that could change nerve temperature, such as differences in muscle mass or regional blood flow. Shorter term studies, using various aldose reductase inhibitors and less mature animals than the present study, tend to show more marked beneficial effects $[8,9,21]$ than were apparent in our 3 month group.

Axon growth was normal in Sorbinil-treated diabetic groups. The reason for this is unclear, but Sidenius [3] suggested that axon growth may be restricted by lack of substrate availability due partly to slowing of some components of orthograde transport in diabetes. Tomlinson et al. [9] demonstrated that Sorbinil treatment normalised choline acetyltransferase transport, as did dietary myo-inositol supplementation. If this represents a general effect on transport, then it could explain the present axon growth and conduction velocity effects of Sorbinil, and merits further investigation.

Another morphological finding, the increase in myelin area and consequent reduction in axon/myelin ra- 
tio in untreated diabetic rats, is in good agreement with some previous light and electron microscopic studies [4, $13,19]$ using relatively mature animals. The cause of myelin expansion is obscure. As the area occupied by the myelin sheath was measured, the results do not necessarily suggest that more myelin was laid down in diabetic animals. Instead a lesser or normal amount of myelin could occupy a larger space. This could be due to sorbitol accumulation in the Schwann cells, resulting in osmotic expansion [1]. The observation that Sorbinil treatment normalised axon/myelin ratios and reduced nerve sorbitol and fructose supports this view. It is likely that the levels of sorbitol and fructose measured in this study would be sufficient to sustain the expansion, provided they were confined to the myelin sheath.

The reduction in axon circularity seen in the present study supports the observations of Sugimura et al. [13]. They suggested that the cause was axonal shrinkage due to hyperosmolarity of the extracellular fluid in diabetes. Axonal shrinkage would result in reduced axon/myelin ratios if the myelin was unaffected by hyperosmolarity. However, the quantities of nerve sorbitol and fructose found in the present study would only cause a very small increase in extracellular osmolarity, and the circularity changes observed are insufficient to account for observed axon/myelin ratio changes, although they may be a minor contributory factor.

The observed myelin changes clearly did not have great functional consequences, but over a longer period, if the insulating properties of the myelin were reduced by swelling or changes in composition, then reduced conduction velocity could result. Myelin expansion could then lead to Schwann cell damage and demyelination [1], as seen in some diabetic patients [22]. The finding that myelin area increases, while axon area decreases with diabetes, suggests that morphometric studies based solely on nerve fibre diameter or area measurements should be interpreted with caution. Thus, in the present work, diabetes had little effect on mean fibre diameter.

Although the morphometric profile of diabetic nerves was normalised by Sorbinil treatment at 3 months, conduction velocity improvements were not substantial until 6 months. This suggests that other nonmorphological factors contribute to reduced conduction velocity in diabetes. The connection between sorbitol accumulation, reduced nerve myo-inositol and nerve dysfunction has attracted great interest. Aldose reductase inhibitors and dietary myo-inositol supplements improved diabetic nerve function $[2,8,23]$ in short-term experiments on rats that were younger than those used in the present investigation. Other studies, which failed to demonstrate the benefical effects of myo-inositol supplements, used mature rats $[10,24]$. In the present study, there was a myo-inositol depletion at 3 but not 6 months in the DC groups, which suggests that the myo-inositol effect could be transient, lasting only until the metabolic derangement reaches a steady state. This argument is supported by long-term studies using rats with 5 [25], 8-12 [26], or 14 months [5] of diabetes which found myo-inositol levels within the normal range. Thus, whilst it is established that reductions in myo-inositol contribute to neurological disturbances in short term experimental diabetes, the present findings suggest that, in the long term, alterations in myo-inositol are not necessary for the functional deficit, which can be explained by a reduction in axon size coupled with possible Schwann cell dysfunction. This conclusion is further supported by data from other species. Myo-inositol levels are normal in spontaneously diabetic $\mathrm{db} / \mathrm{db}$ or streptozotocin-treated mice [27]. However, conduction deficits have been measured in several sensory and motor nerve branches $[28,29]$. Anatomical differences, particularly a reduction in fibre size, have been seen with diabetes [28].

Acknowlegements. This work was supported by Pfizer Ltd. MBL was in receipt of a Pfizer Central Research studentship. We are grateful to Dr. K.R.W.Gillon of Pfizer Ltd for helpful discussions. We also thank Dr. A. K. Sharma and the Anatomy Department of Aberdeen University for facilities and technical assistance in preparing nerves for histology, and Dr. M.A. Cotter for advice and use of equipment during nerve morphometric measurements.

\section{References}

1. Gabbay KH (1973) The sorbitol pathway and the complications of diabetes. N Eng J Med 288: 831-836

2. Greene DA, Levis RA, Lattimer SA, Brown MJ (1982) Selective effects of myo-inositol administration on sciatic and tibial motor nerve conduction parameters in the streptozotocin-diabetic rat. Diabetes 31: 573-578

3. Sidenius $P(1982)$ The axonopathy of diabetic neuropathy. Diabetes $31: 356-363$

4. Jakobsen J (1976) Axonal dwindling in early experimental diabetes. 1. A study of cross sectioned nerves. Diabetologia 12:539-546

5. Greene DA, De Jesus PV, Winegrad AI (1975) Effects of insulin and dietary myo-inositol on impaired peripheral motor nerve conduction velocity in acute streptozotocin diabetes. J Clin Invest 55: 1326-1336

6. Clements RS (1979) Diabetic neuropathy - new concepts of its etiology. Diabetes 28: 604-611

7. Yue DK, Hanwell MA, Satchell PM, Turtle JR (1982) The effect of an aldose reductase inhibitor on motor nerve conduction velocity in diabetic rats. Diabetes 31: 789-794

8. Gillon KRW, Hawthorne JN, Tomlinson DR (1983) Myo-inositol and sorbitol metabolism in relation to peripheral nerve function in experimental diabetes in the rat: the effect of aldose reductase inhibition. Diabetologia 25:365-371

9. Tomlinson DR, Moriarty RJ, Mayer JH (1984) Prevention and reversal of defective axonal transport and motor nerve conduction velocity in rats with experimental diabetes by treatment with the aldose reductase inhibitor Sorbinil. Diabetes 33: 470-476

10. Thomas PK, Jefferys JGR, Sharma AK, Bajada S (1981) Nerve conduction velocity in experimental diabetes in the rat and rabbit. J Neurol Neurosurg Psychiatry 44: 233-238

11. Palmano KP, Whiting PH, Hawthorne JN (1977) Free and lipid myo-inositol in tissues from rats with acute and less severe streptozotocin-induced diabetes. Biochem J 167: 229-235

12. Dyck PJ, Karnes J, Lais A, Lofgren EP, Stevens JC (1984) Pathological alterations of the peripheral nervous system of humans. In: Dyck PJ, Thomas PK, Lambert EH, Bunge R (eds) Peripheral neuropathy, 2nd edn. Saunders, Philadelphia, pp 760-870 
13. Sugimura K, Windebank A, Natarajan V, Lambert E, Schmid H, Dyck PJ (1980) Interstitial hyperosmolarity may cause axis cylinder shrinkage in streptozotocin diabetic nerve. J Neuropathol Exp Neurol 39: 710-721

14. Harding JP (1949) The use of probability paper for the graphical analysis of polymodal frequency distributions. J Mar Biol Ass UK 28: $141-153$

15. Birren JE and Wall PD (1956) Age changes in conduction velocity, refractory period, number of fibers, connective tissue space and blood vessels in sciatic nerve of rats. J Comp Neurol 104: 1-16

16. Jefferys JGR, Brismar T (1980) Analysis of peripheral nerve function in streptozotocin diabetic rats. J Neurol Sci 48: 435-444

17. Greene DA, Yagihashi S, Lattimer SA, Sima AAF (1984) Nerve $\mathrm{Na}^{+}-\mathrm{K}^{+}$-ATPase, conduction, and myo-inositol in the insulin-deficient BB rat. Am J Physiol 247: E534-E539

18. Sharma AK, Thomas PK (1974) Peripheral nerve structure and function in experimental diabetes. J Neurol Sci 23:1-15

19. Jakobsen J (1979) Early and preventable changes of peripheral nerve structure and function in insulin-deficient diabetic rats. $J$ Neurol Neurosurg Psychiatry 42: 509-518

20. Zemp C, Bestetti G, Rossi GL (1981) Morphological and morphometric study of peripheral nerves from rats with streptozotocin induced diabetes mellitus. Acta Neuropathol (Berl) 53:99-106

21. Kikkawa R, Hatanaka I, Yasuda H, Kobayashi N, Shigeta Y (1984) Prevention of peripheral nerve dysfunction by an aldose reductase inhibitor in streptozotocin-diabetic rats. Metabolism 33: 212-214

22. Thomas PK, Lascelles RG (1966) The pathology of diabetic neuropathy. Q J Med 34: 488-509

23. Mayer JH, Tomlinson DR (1983) Prevention of defects of axonal transport and nerve conduction velocity by oral administration of myo-inositol or an aldose reductase inhibitor in streptozotocindiabetic rats. Diabetologia 25: 433-438
24. Jefferys JGR, Palmano KP, Sharma AK, Thomas PK (1978) Influence of dietary myoinositol on nerve conduction and phospholipids in normal and diabetic rats. J Neurol Neurosurg Psychiatry 41: 333-339

25. Stewart MA, Sherman WR, Kurien MM, Moonsammy GI, Wisgerhof M (1967) Polyol accumulations in nerve tissue of rats with experimental diabetes and galactosemia. J Neurochem 14: 1057-1066

26. Poulsom R, Boot-Handforth RP, Heath H (1983) The effect of long-term treatment of streptozotocin-diabetic rats with an aldose reductase inhibitor. Exp Eye Res 37: 507-515

27. Whiteley SJ, Tomlinson DR (1985) Motor nerve conduction velocity and nerve polyols in mice with short-term genetic or streptozotocin-induced diabetes. Exp Neurol 89: 314-321

28. Moore SA, Peterson RG, Felten DL, Cartwright TR, O'Connor BL (1980) Reduced sensory and motor conduction velocity in 25-week-old diabetic [C57BL/Ks(db/db)] mice. Exp Neurol 70: $548-555$

29. Sima AAF, Robertson DM (1978) Peripheral neuropathy in the mutant diabetic mouse $(\mathrm{C} 57 / \mathrm{Ks}(\mathrm{db} / \mathrm{db}))$. Acta Neuropathol (Berl) 41: 85-89

Received: 28 May 1985

and in revised form: 23 December 1985

Dr. N.E.Cameron

Department of Physiology

Marischal College

Aberdeen University

Aberdeen AB9 1AS

Scotland, UK 